\title{
Solubility of Nutraceutical Compounds in Generally Recognized as Safe Solvents at $298 \mathrm{~K}$
}

\author{
Remil Aguda and Chau-Chyun Chen
}

\begin{abstract}
The solubility of two model nutraceuticals, quercetin and sclareol, were measured in organic solvents at 298 K by UV-Vis spectrophotometry and gas chromatography, respectively. Thermodynamic models for solid-liquid phase equilibria are used to correlate and predict the solubility of quercetin and sclareol in organic solvents which are Generally Recognized as Safe by the United States Food and Drug Administration. For both quercetin and sclareol, the NRTL-SAC model satisfactorily correlates the experimental data while the COSMO-SAC solubility prediction results are off by more than one natural logarithm of mole fraction of the experimental data.
\end{abstract}

Index Terms-Generally recognized as safe solvents nutraceutical, NRTL-SAC, quercetin, sclareol, solubility, COSMO-SAC.

\section{INTRODUCTION}

Nutraceuticals are organic compounds naturally found in plants and animals which have health benefits but not necessarily able to treat, diagnose or cure any disease. These compounds are taken to prevent disease or enhance the physical well-being of humans [1]. In this study, quercetin and sclareol are selected as model nutraceutical compounds for studying their solubility because of their stability at room temperature, availability from commercial suppliers and their potential uses in commercial product formulations. Fig. 1 shows the chemical structure of quercetin and sclareol.

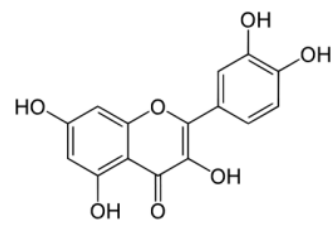

(a)

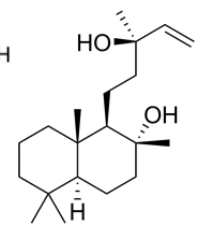

(b)
Fig. 1. Chemical structure of quercetin (a) and sclareol (b) (from wikipedia website).

Manuscript received January 5, 2016; revised February 22, 2016 Funding from the University of the Philippines Los Baños Research Trust Fund are acknowledged for the support of the experimental part on quercetin and the United States National Science Foundation and North Carolina Biotechnology Center for the support of the experimental part on sclareol. Chau-Chyun Chen gratefully acknowledges the financial support of the Jack Maddox Distinguished Engineering Chair Professorship in Sustainable Energy sponsored by the J. F Maddox Foundation.

Remil Aguda was with the Institute of Chemistry, University of the Philippines Los Baños Laguna Philippines 4031 and Department of Chemical and Biomolecular Engineering, North Carolina State University, Raleigh, North Carolina 27695, USA (e-mail: rmaguda@ncsu.edu).

Chau-Chyun Chen is with the Department of Chemical Engineering, Texas Tech University, Lubbock, Texas 79409, USA (e-mail: chauchyun.chen@ttu.edu).
Belonging to the flavonoid group of antioxidant molecules, quercetin is a naturally found compound in fruits and vegetables, where it provides flavor and color. It has been shown to prevent cancer and cardiovascular diseases from studies on its anti-carcinogenic activity of extracts from cooked fruits and vegetables on several mutagens [2]. It is readily available commercially as a hydrate and stable at room temperature. The solubility of quercetin and other flavonoids has been quantified in organic solvents such as acetonitrile, acetone and tert-amyl alcohol [3]. However, not all of these organic solvents are fit as extracts for human consumption The United States Food and Drug Administration listed solvents which are Generally Recognized as Safe (GRAS) for human consumption, as proven by toxicological studies and medical studies showing no adverse effect on human health over their use in food over a long period of time [4]. These solvents are also used as food additives, as established by scientific procedures and the substance's common use in food. Flavoring substances can also be considered GRAS solvents [5], [6] for extraction, purification and formulation of nutraceutical products. Ethanol is a GRAS solvent used in supercritical fluid extraction studies for quercetin from grape seeds [7]. The solubility of quercetin in mixtures of water, methanol and ethanol has also been quantified and correlated [8]-[10]. It is particularly striking that there is a considerable disagreement over the solubility of quercetin in water [8]. In addition to anhydrous quercetin, quercetin dihydrate is also present as a solid form in water [10]. The solubility of quercetin dihydrate in water is so low that it is below the lower limit of detection [11]. Some of these literature solubility data are summarized in Table I.

Sclareol is a highly water-insoluble compound that belongs to the labdane type diterpenes and characterized as a biologically active molecule, due to its cytotoxic and cytostatic effects against human leukemic cell lines [12]. This compound is manufactured from its plant source, Salvia sclarea, using hexane, water and ethanol as extraction and purification solvents, respectively. Ethyl lactate has been studied as an alternative GRAS solvent for its extraction [13]. There are no published solubility data for sclareol in organic solvents. The sclareol solubility in water at $298.15 \mathrm{~K}$ is estimated to be $0.08174 \mathrm{mg} / \mathrm{L}$, or $4.8 \mathrm{e}-9$ in mole fraction [14]. This study investigated the solubility of quercetin and sclareol in GRAS solvents with the interest in exploring the use of GRAS solvents to solubilize more quercetin or sclareol during the extraction process from its food sources. GRAS solvents, which have higher solubilities than existing solvents used in their respective manufacturing processes, can also be good candidates for formulation studies on nutraceuticals since these solvent systems can contain higher amounts than 
ethanol, and eventually deliver higher doses to consumers.

\begin{tabular}{lclll}
\multicolumn{4}{c}{ TABLE I: SOLUBILITY OF QUERCETIN IN ORGANIC SOLVENTS } \\
\hline Solvent & mmol/L & mole fraction & T/K & References \\
& & & & \\
\hline acetonitrile & 5.40 & 0.00028 & 323 & 3 \\
& 6.80 & 0.00036 & 333 & 3 \\
& 7.05 & 0.00037 & 343 & 3 \\
acetone & 80.08 & 0.00588 & 323 & 3 \\
tert-amyl & 67.01 & 0.00734 & 323 & 3 \\
alcohol & & & & \\
water & & 0.000055 & 298.6 & 9 \\
water & & $0.00000013^{\text {a }}$ & 298.8 & 10 \\
methanol & & 0.00092 & 298.6 & 9 \\
ethanol & & 0.00153 & 298.6 & 9
\end{tabular}

${ }^{\mathrm{a}}$ anhydrous quercetin

\section{EXPERIMENTAL SECTION}

\section{A. Materials and Methods}

Quercetin in solid form (> 95\% by HPLC) was obtained from Sigma-Aldrich (St. Louis, MO). The organic solvents were obtained from different chemical manufacturers with known percent purity measured by gas or liquid chromatography: ethyl lactate (Wako, 95\%), ethanol (JT Baker, 99.9\%), 2-propanol (JT Baker, $99.5 \%$ ), 1-propanol (ACI Labscan, 99.5\%), butyl butyrate (Aldrich, 98\%), and acetonitrile (ACI Labscan, 99.7\%).

The melting temperature and heat of fusion is determined using differential scanning calorimeter Model Q100 (TA Instruments, New Castle, DE). All measurements were done at atmospheric pressure, near $0.1 \mathrm{MPa}$.

For determining the solubility of quercetin in these organic solvents, approximately 10 grams of quercetin was added to $10 \mathrm{~mL}$ of the solvent until some of the solid solute no longer dissolves. The mixture was stirred for at least 12 hours at 298 $\pm 5 \mathrm{~K}$, decanted and diluted with the solvent. The concentration of the saturated solution was measured by interpolating the absorbance of the diluted sample of the saturated solution in a plot of absorbance versus concentration of solution with known quercetin concentrations. The absorbance was taken at $374 \mathrm{~nm}$ using UV-mini spectrophotometer model 1240 (Shimadzu Corporation, Japan).

For the determination of the solubility of sclareol in organic solvents, a slurry of the organic solvent and sclareol is stirred for at least 12 hours at $298 \pm 2 \mathrm{~K}$, filtered, diluted and analyzed by gas chromatography. Sclareol (> $95 \%$ purity) was obtained from Sigma-Aldrich (St. Louis, MO). The organic solvents used were n-hexane, isohexane, ethanol, 1-propanol (99.9 \% purity, HPLC Grade) from Sigma-Aldrich, toluene, acetonitrile, tetrahydrofuran, cyclohexane, methanol (99.9\% purity, HPLC Grade) from Fisher Scientific, heptadecane, heptadecanol (99\% purity) from Fisher Scientific, ethyl-s-lactate, ethyl acetate, ethyl hexanoate (98\% purity) from Sigma-Aldrich, acetone, triethanolamine, formamide, decahydronaphthalene, N,N-dimethylformamide, dimethyl sulfoxide (99\% purity) from Sigma-Aldrich, and butyl butyrate ( $99.9 \%$ purity) from Eastman. A Teflon membrane (with pore size of 0.45 micron, contained in a Whatman syringeless autovial) from Fisher
Scientific was used for filtering the samples.

Gas chromatography (GC) has been widely used in the quantitative analysis of sclareol and natural product extracts containing sclareol [13]. Pure sclareol (95 \% by GC) standard was obtained from Sigma Aldrich (St. Louis, MO). The adopted gas chromatography method was developed by Danehower and coworkers [15]. An Agilent 6890N gas chromatograph equipped with a 20 meter DB-5HT column (0.32 mm diameter, 0.25 micron thickness, $\mathrm{J} \& \mathrm{~W}$ Scientific) was used for analysis. 0.5 microliter of a solution containing the sample was analyzed using splitless injection and an injector temperature of $275^{\circ} \mathrm{C}$. Flame ionization detection was utilized with a detector temperature of $310^{\circ} \mathrm{C}$. The column flow of helium carrier gas was set to a linear gas velocity of $\sim 35 \mathrm{~cm} / \mathrm{sec}$. The initial oven temperature was 160 ${ }^{\circ} \mathrm{C}$, followed by a $4{ }^{\circ} \mathrm{C} / \mathrm{min}$ temperature increase to $310^{\circ} \mathrm{C}$ as the final temperature. The oven temperature increase began upon injection and the final temperature was maintained for 30 minutes. Data were collected using the Perkin-Elmer Total Chrom 6.2 chromatographic analysis system. Quantitation of sclareol was done using the external standard method. Heptadecane and heptadecanol in toluene $(52 \mathrm{mg} / \mathrm{L}$ and 56 $\mathrm{mg} / \mathrm{L}$, respectively) were used as internal standards to check the reproducibility of the injection of the sample. In preparing the sclareol solution prior to GC analysis, $0.20 \mathrm{~mL}$ of the sclareol solution was combined with $1.0 \mathrm{~mL}$ of the internal standard, vortexed for about 10 seconds and transferred into 2 $\mathrm{mL}$ autosampler vials containing 250 microliter sample vial inserts (Agilent Technologies, Palo Alto, CA). In the analysis of pure sclareol samples, no derivatization of sclareol solution was done. A calibration curve for each solvent was prepared. A calibration curve is the basis for determining the concentration (in $\mathrm{g} / \mathrm{L}$ ) of sclareol in an unknown sample. The peak area of the sample calculated based upon the formula of the standard curve. The $R^{2}$ values of the standard curves typically are in the range of 0.90 to 0.99 . A blank run was included in the analysis of each batch of samples. The blank consisted of the pure solvent and an internal standard.

\section{B. Experimental Results}

The solubility of quercetin in various organic solvents were determined at 298 K [16] as shown in Table II. Five samples were tested for each solubility data point. Among the tested solvents, ethanol, ethyl lactate and 2-propanol are listed as GRAS by US FDA. Butyl butyrate and acetonitrile were chosen because of their availability. Ethyl lactate and acetonitrile gave the highest and lower solubilities, respectively.

TABLE II: MEASURED SOLUBILITY OF QUERCETIN IN ORGANIC SOLVENTS AT $298 \mathrm{~K}(N=5)$

\begin{tabular}{lll}
\hline Solvent & $\% \mathrm{w} / \mathrm{w}$ & mole fraction \\
\hline ethyl lactate & 6.7 & 0.0271 \\
ethanol & 3.2 & 0.0050 \\
2-propanol & 2.7 & 0.0055 \\
1-propanol & 2.6 & 0.0052 \\
butyl butyrate & 1.4 & 0.0065 \\
acetonitrile & 1.1 & 0.0015 \\
\hline
\end{tabular}


The solubility of sclareol in various organic solvents were determined at $298 \mathrm{~K}$ as shown in Table III. At least three samples were tested for each solubility data point. The highest solubility of sclareol is in butyl butyrate and the lowest solubility is in formamide. Of the 17 solvents tested, the GRAS solvents are acetone, 1-propanol, ethanol, ethyl acetate, ethyl lactate, ethyl hexanoate and butyl butyrate. We found no prior measurements for sclareol for these solvents as far as our literature search has revealed.

For comparison with literature values, Table IV contains reported solubility values for quercetin [17]-[19]. Differential scanning calorimetery determined the melting temperature and heat of fusion of quercetin and sclareol as shown in Table IV.

TABLE III: SOLUBILITY OF SCLAREOL IN ORGANIC SOLVENTS AT 298 K $(N \geq$ 3)

\begin{tabular}{lll}
\hline Solvent & $\% \mathrm{w} / \mathrm{w}$ & mole fraction \\
\hline butyl butyrate & 22.1 & 0.1170 \\
ethyl hexanoate & 15.3 & 0.0778 \\
ethyl lactate & 11.0 & 0.0452 \\
ethyl acetate & 11.5 & 0.0358 \\
triethanolamine & 2.1 & 0.0104 \\
N,N-dimethylformamide & 4.8 & 0.0118 \\
formamide & 0.1 & 0.0002 \\
acetonitrile & 3.9 & 0.0053 \\
dimethylsulfoxide & 11.1 & 0.0307 \\
tetrahydrofuran & 11.4 & 0.0293 \\
Acetone & 15.2 & 0.0326 \\
1-propanol & 11.6 & 0.0250 \\
Ethanol & 13.2 & 0.0222 \\
methanol & 7.1 & 0.0079 \\
Toluene & 13.3 & 0.0438 \\
decahydronaphthalene & 6.5 & 0.0300 \\
isohexane & 17.7 & 0.0135 \\
cyclohexane & 0.0554 \\
n-hexane & 0.0046 \\
\hline
\end{tabular}

TABLE IV: MELTING TEMPERATURE AND HEAT OF FUSION OF QUERCETIN AND SCLAREOL MEASURED BY DIFFERENTIAL SCANNING CALORIMETRY

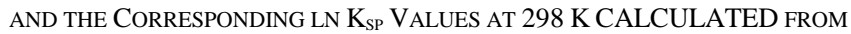

\begin{tabular}{ccccc}
\multicolumn{5}{c}{ EQ. (1) } \\
\hline $\begin{array}{c}\text { Nutraceutica } \\
1 \text { Compound }\end{array}$ & $\begin{array}{l}\text { Melting } \\
\text { temperature, }{ }^{\circ} \mathrm{C}\end{array}$ & $\begin{array}{l}\text { Heat of } \\
\text { fusion, } \\
\mathrm{kJ} / \mathrm{mol}\end{array}$ & $\begin{array}{c}\ln \mathrm{K}_{\mathrm{sp}} \\
\text { at } 298 \mathrm{~K}\end{array}$ & Reference \\
\hline Quercetin & 318.0 & 32.9 & -6.585 & this work \\
& 320.0 & 41.5 & -8.334 & 16 \\
& 326.0 & $\begin{array}{c}\text { Not } \\
\text { reported }\end{array}$ & $\mathrm{NA}$ & 17 \\
& 315.0 & 51.1 & -10.154 & 18 \\
Sclareol & 103.3 & 28.7 & -2.411 & this work \\
\hline
\end{tabular}

\section{THERMODYNAMIC MODELING SECTION}

Solubility modeling of drug-like molecules in pure solvents and mixed solvents has been extensively studied in recent years [20]-[22]. For a given polymorph, the solubility of a solid organic nonelectrolyte can be approximated by the following expression:

$$
\ln x_{i}^{s a t}=\ln K_{s p}-\ln \gamma_{i}^{s a t}=\frac{\Delta H_{\text {fus }}}{R}\left(\frac{1}{T_{m}}-\frac{1}{T}\right)-\ln \gamma_{i}^{s a t}
$$

where $x_{i}^{\text {sat }}$ is the mole fraction of solute $i$ dissolved in the solvent phase at saturation, $K_{\mathrm{sp}}$ the solubility product constant, $\gamma_{i}^{\text {sat }}$ the activity coefficient of solute $i$ dissolved in the liquid phase at saturation, $\Delta H_{\text {fus }}$ the enthalpy of fusion of the solute, $R$ the gas constant, $T_{m}$ the melting temperature of the solute, and $T$ the system temperature. Eq. (1) shows that, given a solid polymorph and a system temperature, the solute solubility is determined by the activity coefficient of the solute in solution.

Among the various activity coefficient models widely used in the industry, Non-Random Two-Liquid Segment Activity Coefficient (NRTL-SAC) model and COnductor like Screeing MOdels (COSMO) derived from solvation thermodynamics are considered perhaps among the most successful predictive activity coefficient models to-date [21]. COSMO-RS [23] and COSMO-SAC [24] are the two main variants of COSMO models. In this work, NRTL-SAC and COSMO-SAC are applied to model solubility of quercetin and sclareol in various GRAS solvents.

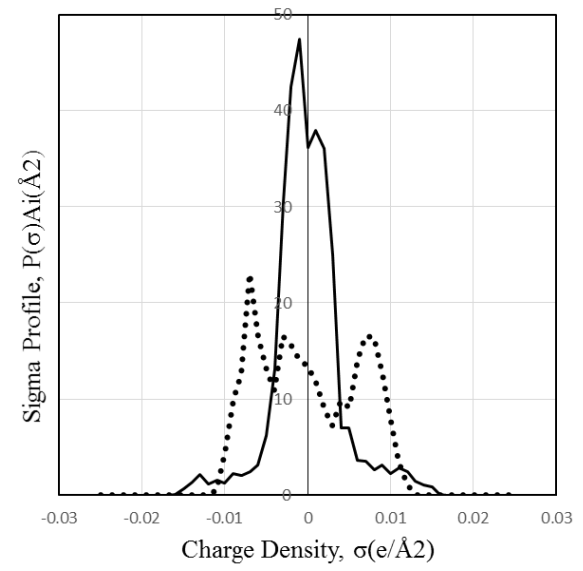

Fig. 2. Sigma profiles of quercetin (dotted line) and sclareol (solid line).

COSMO-SAC computes solute activity coefficients in solution based on so-called molecular "sigma profile," i.e., a histogram of charge density distribution over the molecular surface generated from molecular structure, conformation, and quantum mechanical calculations. Open source web-based sigma profile database, VT-2005 sigma profile database, is available for solvents and small molecules (www.design.che.vt.edu) [25]. VT-2005 database includes sigma profiles of 1432 common compounds and it is further supplemented by VT-2006 database [26], which includes additional 32 solvents and 206 primarily larger pharmaceutical compounds. In this study, the solvent sigma profiles are retrieved directly from VT-2005 sigma profile database. The quercetin and sclareol sigma profiles are generated with the same computational procedure used by VT-2005 sigma profile database using DMol3 module of Accelrys' Materials Studio software [27]. The generated 
sigma profiles are shown in Fig. 2. The calculated cavity volume are $284.4 \AA 3$ for quercetin and $427.6 \AA 3$ for sclareol. It is interesting that the calculated cavity volumes differ so much even though molecular weights are similar for the two molecules $(M w=302.2$ for quercetin and 308.5 for sclareol).

NRTL-SAC represents molecules with four conceptual segments that are selected to reflect major molecular surface characteristics of inter-molecular interactions: hydrophobic $(\mathrm{X})$, polar attractive $(\mathrm{Y}-)$, polar repulsive $(\mathrm{Y}+)$, and hydrophilic (Z). Each component in solution is represented with a set of conceptual segment numbers of these four types. Activity coefficients of solutes and solvents in the solution are then calculated as long as all of the components in the mixture have been characterized with their equivalent conceptual segment numbers.

Conceptual segment numbers of the solvents are reported in Table V. Many of them are taken directly from the literature [20]. The conceptual segment numbers for ethyl lactate, butyl butyrate, isoamyl acetate, glycerin, and octanoic acid are identified in this work with a procedure consistent with those reported in the literature [20].

TABLE V: NRTL-SAC CONCEPTUAL SEGMENT NUMBERS FOR SOLVENTS,

\begin{tabular}{|c|c|c|c|c|c|c|}
\hline \multicolumn{7}{c}{ QUERCETIN AND SCLAREOL } \\
\hline Solvent & $\mathrm{X}$ & $\mathrm{Y}-$ & $\mathrm{Y}+$ & $\mathrm{Z}$ & References \\
\hline methanol & 0.090 & 0.139 & 0 & 0.594 & {$[1]$} \\
\hline ethanol & 0.251 & 0.030 & 0 & 0.630 & {$[1]$} \\
\hline 1-propanol & 0.374 & 0.013 & 0 & 0.530 & {$[1]$} \\
\hline 2-propanol & 0.332 & 0 & 0 & 0.636 & {$[1]$} \\
\hline acetic acid & 0.048 & 0.222 & 0.195 & 0.206 & {$[1]$} \\
\hline octanoic acid & 0.755 & 0 & 0 & 0.205 & this work \\
\hline acetonitrile & 0.018 & 0.131 & 0.883 & 0 & {$[1]$} \\
\hline acetone & 0.131 & 0.109 & 0.513 & 0 & {$[1]$} \\
\hline tetrahydrofuran & 0.235 & 0.040 & 0.320 & 0 & {$[1]$} \\
\hline water & 0 & 0 & 0 & 1.000 & {$[1]$} \\
\hline glycerin & 0 & 0 & 0.355 & 1.135 & this work \\
\hline ethyl acetate & 0.339 & 0.058 & 0.441 & 0 & {$[1]$} \\
\hline butyl butyrate & 0.751 & 0.286 & 0.933 & 0 & this work \\
\hline ethyl lactate & 0.210 & 0.309 & 0.619 & 0 & this work \\
\hline isoamyl acetate & 0.582 & 0.156 & 0.734 & 0 & this work \\
\hline $\mathrm{N}, \mathrm{N}$-dimethylformamide & 0.180 & 0.752 & 0.254 & 0 & {$[1]$} \\
\hline formamide & 0 & 0.089 & 0.341 & 0.252 & {$[1]$} \\
\hline dimethylsulfoxide & 0 & 1.114 & 0 & 0 & {$[1]$} \\
\hline n-hexane & 1.000 & 0 & 0 & 0 & {$[1]$} \\
\hline cyclohexane & 0.892 & 0 & 0 & 0 & {$[1]$} \\
\hline toluene & 0.604 & 0 & 0.304 & 0 & {$[1]$} \\
\hline anisole & 0.536 & 0.010 & 0.653 & 0 & {$[1]$} \\
\hline quercetin & 2.456 & 0 & 1.558 & 1.504 & this work \\
\hline sclareol & 0.793 & 0 & 0.065 & 0.160 & this work \\
\hline & & & & & \\
\hline & & & & 0 \\
\hline
\end{tabular}

TABLE VI: SOLUBILITY CORRELATION AND PREDICTION RESULTS FOR QUERCETIN IN GRAS SOLVENTS AT 298 K

\begin{tabular}{|c|c|c|c|c|}
\hline $\begin{array}{c}\text { Solvent } \\
\text { ethyl lactate }\end{array}$ & $\begin{array}{c}\text { Measured solubility } \\
\text { (in mole fraction) }\end{array}$ & $\begin{array}{c}\text { NRTL-SAC } \\
\text { Correlation }\end{array}$ & $\begin{array}{c}\text { NRTL-SAC } \\
\text { Prediction }\end{array}$ & $\begin{array}{c}\text { COSMO-SAC } \\
\text { Prediction }\end{array}$ \\
\hline $\begin{array}{c}\text { 1-propanol } \\
\text { 2-propanol } \\
\text { butyl butyrate }\end{array}$ & 0.0271 & 0.0238 & & 0.0099 \\
\hline $\begin{array}{c}\text { acetonitrile } \\
\text { water }\end{array}$ & 0.0050 & 0.0048 & & 0.0026 \\
\hline $\begin{array}{c}\text { methanol } \\
\text { ethyl acetate }\end{array}$ & 0.0052 & 0.0072 & & 0.0015 \\
\hline $\begin{array}{c}\text { acetic acid } \\
\text { anisole }\end{array}$ & 0.0065 & 0.0043 & & 0.0027 \\
\hline $\begin{array}{c}\text { isoamyl acetate } \\
\text { glycerin }\end{array}$ & 0.0015 & & & 0.0031 \\
\hline $\begin{array}{c}\text { octanoic acid } \\
\text { lactic acid } \\
\text { stearic acid } \\
\text { ethyl vanillin }\end{array}$ & & & 0.0013 & 0.0242 \\
\hline $\begin{array}{c}\text { Average error in ln } \mathrm{x} \text { for the first 6 solvents } \\
\text { a Ksp regressed from the first 6 solvents }\end{array}$ & 0.12 & 0.0460 & 0.0047 \\
\hline
\end{tabular}

\section{A. Quercetin Modeling Results}

Shown in Table V, the conceptual segment numbers for quercetin are regressed from the quercetin solubility data in the six solvents reported in Table II. The conceptual segment numbers suggest quercetin molecule surface contains significant hydrophobic, polar repulsive, and hydrophilic regions. Also regressed from the quercetin solubility data is the solubility product constant for quercetin ( $\ln K s p=-6.513)$. This regressed value is consistent with the value $(\ln K s p=$ -6.585) calculated from melting temperature and heat of fusion of quercetin we measured and reported in Table 4. Table VI reports the NRTL-SAC model results for the solubility of quercetin in various solvents. The results include the correlation results for quercetin solubility in the six solvents with data and the prediction results for quercetin solubility in other solvents without data. Also shown in Table VI are the COSMO-SAC solubility prediction results. Note that the solubility product constant used in computing quercetin solubility with COSMO-SAC has been optimized with the measured quercetin solubility data for the six solvents $\left(\ln K_{s p}=-4.721\right)$.

NRTL-SAC correlates very well the measured solubility quercetin data for the six solvents. The average error in natural logarithm of mole fraction for the measured solubility and the correlated solubility is merely 0.12 . The COSMO-SAC solubility predictions for quercetin are too high for acetonitrile and too low for the three alcohol and two ester solvents. The average error in natural logarithm of mole fraction with COSMO-SAC is 1.02. Among the GRAS solvents, NRTL-SAC suggests esters and acids to be good solvents for quercetin. Both NRTL-SAC and COSMO-SAC predict very low water solubility for quercetin. Interestingly, NRTL-SAC predicts very low quercetin solubility in glycerin while COSMO-SAC predicts signficant quercetin solubility in glycerin. A parity plot showing the correlation results with NRTL-SAC and the prediction results with COSMO-SAC for the quercetin solubility in the six solvents is shown in Fig. 3.

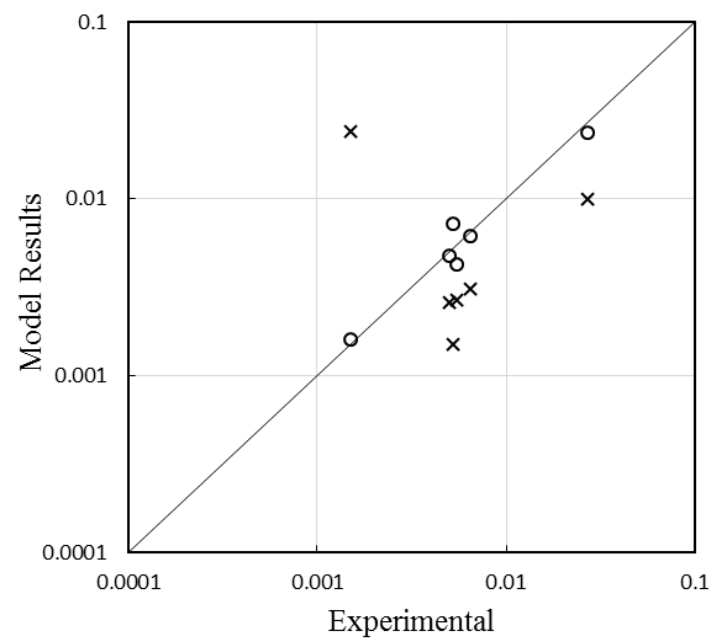

Fig. 3. Parity plot showing NRTL-SAC correlation results ( $\mathrm{O}$ ) and COSMO-SAC prediction results (x) against experimental data for quercetin.

\section{B. Sclareol Modeling Results}

The conceptual segment numbers for sclareol are regressed from the sclareol solubility data in eight selected solvents to cover hydrophobic (toluene, ethyl acetate), polar (acetone, acetonitrile, tetrahydrofuran, ethyl acetate, toluene), and 
hydrophilic solvents (methanol, ethanol, and 1-propanol). Shown in Table V, the conceptual segment numbers suggest sclareol molecule surface is mainly hydrophobic and with minor hydrophilic region. Also regressed from the data is the solubility product constant for sclareol $\left(\ln \mathrm{K}_{\mathrm{sp}}=-3.016\right)$. This regressed value is line with the value $\left(\ln \mathrm{K}_{\mathrm{sp}}=-2.411\right)$ calculated from melting temperature and heat of fusion of sclareol reported in Table IV. Table VII summarizes the NRTL-SAC model results for the soluility of sclareol in various solvents. The results include the correlation for sclareol solubility in the eight selected solvents and the prediction results for sclareol solubility in the remaining seven solvents with available NRTL-SAC parameters. Also shown in Table VII are the COSMO-SAC solubility prediction results. Note that the solubility product constant used in computing sclareol solubility with COSMO-SAC has been optimized with the measured sclareol solubility data for the eight solvents selected to regress the NRTL-SAC parameters for sclareol. The resulting solubility product constant for COSMO-SAC $\left(\ln \mathrm{K}_{\mathrm{sp}}=-3.210\right)$ is close to that obtained with NRTL-SAC.

TABLE VII: SOLUBILITY CORRELATION AND PREDICTION RESULTS FOR SCLAREOL IN GRAS SOLVENTS AT $298 \mathrm{~K}$

\begin{tabular}{|c|c|c|c|c|}
\hline Solvent & $\begin{array}{c}\text { Measured } \\
\text { solubility (in } \\
\text { mole fraction) }\end{array}$ & $\begin{array}{l}\text { NRTL-SAC } \\
\text { Correlation }\end{array}$ & $\begin{array}{l}\text { NRTL-SAC } \\
\text { prediction }\end{array}$ & $\begin{array}{l}\text { COSMO-SAC } \\
\text { predication }^{\mathrm{a}}\end{array}$ \\
\hline butyl butyrate & 0.1170 & & 0.0445 & 0.0320 \\
\hline ethyl hexanoate & 0.0778 & & & 0.0282 \\
\hline ethyl lactate & 0.0452 & & 0.0232 & 0.0273 \\
\hline ethyl acetate & 0.0358 & 0.0344 & & 0.0446 \\
\hline triethanolamine & 0.0104 & & & 0.0025 \\
\hline $\mathrm{N}, \mathrm{N}$-dimethylformamide & 0.0118 & & 0.0249 & 0.1916 \\
\hline formamide & 0.0002 & & 0.0050 & $6.7 \mathrm{E}-06$ \\
\hline acetonitrile & 0.0053 & 0.0093 & & 0.0012 \\
\hline dimethylsulfoxide & 0.0307 & & 0.0130 & 0.1598 \\
\hline tetrahydrofuran & 0.0293 & 0.0380 & & 0.1873 \\
\hline acetone & 0.0326 & 0.0201 & & 0.0994 \\
\hline 1-propanol & 0.0250 & 0.0313 & & 0.0375 \\
\hline ethanol & 0.0222 & 0.0217 & & 0.0358 \\
\hline methanol & 0.0079 & 0.0067 & & 0.0217 \\
\hline toluene & 0.0438 & 0.0409 & & 0.0072 \\
\hline decahydronaphthalene & 0.0300 & & & 0.0020 \\
\hline isohexane & 0.0135 & & & 0.0020 \\
\hline cyclohexane & 0.0554 & & 0.0371 & 0.0026 \\
\hline n-hexane & 0.0046 & & 0.0370 & 0.0014 \\
\hline water & & & $5.0 \mathrm{E}-06$ & $1.9 \mathrm{E}-08$ \\
\hline Average error in $\ln x$ & & 0.23 & 1.49 & 1.54 \\
\hline
\end{tabular}

${ }^{\mathrm{a}} \mathrm{Ksp}$ regressed form the solubility data for the 8 solvents used in NRTL-SAC correlation

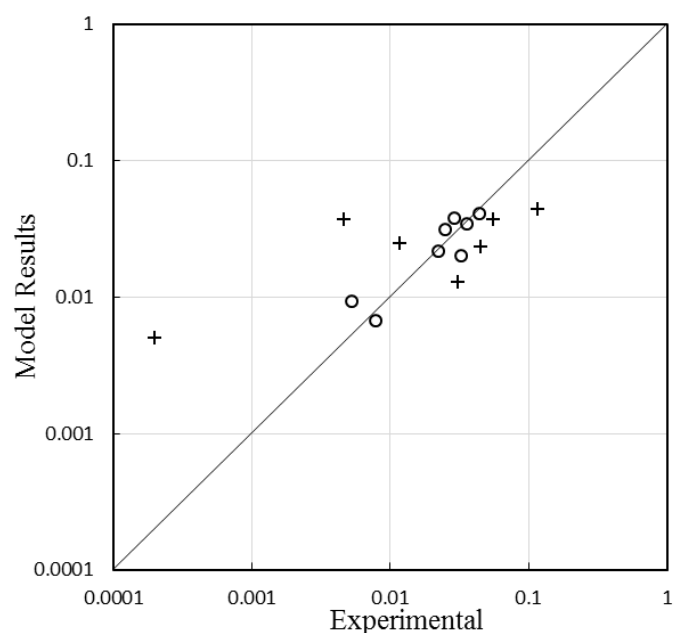

Fig. 4. Parity plot showing NRTL-SAC correlation results (O) and NRTL-SAC prediction results (+) against experimental data for sclareol.

NRTL-SAC correlates very well the measured sclareol solubility data for the eight solvents. The average error in natural logarithm of mole fraction for the measured sclareol solubility and the correlated solubility is 0.23 . When used as a predictive model, the average error in natural logarithm of mole fraction with NRTL-SAC for the remaining seven solvents is 1.49. A main contributor to this large average error is that of n-hexane. NRTL-SAC predicts similar sclareol solubility in cyclohexane and in n-hexane while the data suggest sclareol solubility in n-hexane is at least one order of magnitude lower than that in cyclohexane. A parity plot showing both the correlation results and the prediction results with NRTL-SAC is given in Fig. 4. The NRTL-SAC prediction results seem qualitatively correct.

The average error in natural logarithm of mole fraction with the COSMO-SAC solubility predictions for sclareol is 1.54. The COSMO-SAC predictions are too high for polar solvents including N,N-dimethylformamide, dimethylsulfoxide, tetrahydrofuran, and acetone and too low for hydrophobic solvents including toluene, decahydronaphthalene, isohexane, and cyclohexane. A parity plot showing the COSMO-SAC prediction results is given in Fig. 5. It seems COSMO-SAC fails to provide any trends, even qualitative, for the sclareol solubility in organic solvents. Both NRTL-SAC and COSMO-SAC do predict low water solubility. Like NRTL-SAC, COSMO-SAC also suggests similar sclareol solubility in cyclohexane and in n-hexane.

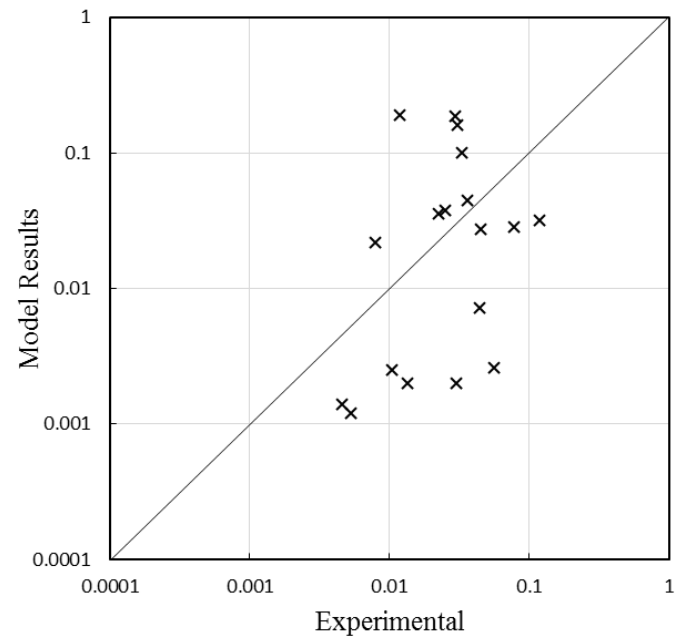

Fig. 5. Parity plot showing COSMO-SAC prediction results (x) against experimental data for sclareol.

\section{CONCLUSION}

The solubility of quercetin and sclareol in organic solvents at $298 \mathrm{~K}$ were measured and reported. Thermodynamic models for solid-liquid phase equilibria are used to correlate and predict the solubility of quercetin and sclareol in organic solvents. For both quercetin and sclareol, NRTL-SAC model satisfactorily correlates the experimental data within semi-quantitative accuracy while COSMO-SAC model prediction results are at best qualitative for these molecules. The correlated data may be the basis for designing an extraction process from its source, purification of the extract and formulation of the final product. The practical use of this data is to know the saturation point of the nutraceutical for extraction from the botanical source, the amount of this 
nutraceutical molecule in a solvent system during separation from the extract and the amount that can be dissolved in a GRAS solvent in the formulated liquid product. Solubility sets the limit for the amount of a solid nutraceutical that can be dissolved in a solvent or group of solvents.

\section{ACKNOWLEDGMENT}

The faculty and staff of the Institute of Chemistry University of the Philippines Los Baños are acknowledged for their technical assistance on the laboratory equipment during the experimental solubility measurements for quercetin. The faculty, students and staff of the Department of Crop Science and Department of Chemical and Biomolecular Engineering at North Carolina State University are acknowledged for their assistance on the sclareol solubility measurements. The authors thank $\mathrm{Md} \mathrm{R}$. Islam in generating from $\mathrm{DMol}^{3}$ the sigma profiles used in the COSMO-SAC calculations.

\section{REFERENCES}

[1] L. Rapport and B. Lockwood, Nutraceuticals, London: Pharmaceutical Press, 2001, pp. 5-8

[2] G. C. M. Williamson, "Bioavailablity and bioefficacy of poly-phenols in humans, II: Review of 93 intervention studies," AmJClinNutr, vol. 81, pp. 2435-2555, 2005.

[3] L. Chebil, C. Humeau, J. Anthoni, F. Dehez, J.-M. Engasser, and M. Ghoul, "Solubility of flavonoids in organic solvents," J. Chem Eng Data, vol. 52, no. 5, pp. 1552-1556, 2007.

[4] Food and Drug Administration D of H and HS, Substances Generally Recognized as Safe U.S. Code of Federal Regulation, Title 21, 2004.

[5] R. L. Smith, S. M. Cohen, J. Doull et al., "Criteria for the safety evaluation of flavoring substances," Food Chem Toxicol, The Expert Panel of the Flavor and Extract Manufacturers Association, vol. 43, no. 8, pp. 1141-1177, 2005.

[6] L. A. Woods and J. Doull, "GRAS evaluation of flavoring substances by the expert panel of FEMA," Regul Toxicol Pharmacol, pp. 48-58, 1991.

[7] A. Chafer, T. Fornari, A. Berna, and R. P. Stateva, "Solubility of quercetin in supercritical $\mathrm{CO}^{2+}$ ethanol as a modifier: Measurements and thermodynamic modelling," J Supercrit Fluids, vol. 32, no. 1-3, pp. 89-96, 2004.

[8] M. H. Abraham, "Acree WEJ. on the solubility of quercetin," $J$ Mol Liq., vol. 197, pp. 157-159, 2014.

[9] R. S. Razmara, A. Daneshfar, and R. Sahraei, "Solubility of quercetin in water + methanol and water + ethanol from (292.8 to 333.8) K," J Chem Eng Data, vol. 55, pp. 3934-3936, 2010.

[10] K. Srinivas, J. W. King, L. R. Howard, and J. K. Monrad, "Solubility and solution thermodynamic properties of quercetin and quercetin dihydrate in subcritical water," J Food Eng., vol. 100, pp. 208-218, 2010.

[11] A. J. Smith, P. Kavuru, L. Wojtas, M. J. Zaworotko, and R. D. Shytle, "Cocrystals of quercetin with improved solubility and oral bioavailability," Mol. Pharmaceutics, vol. 8, pp. 1867-1876, 2011.

[12] I. Kyrikou, A. Georgopoulo, S. Hatziantoniou, T. Mavromoustakos, and C. Demetzos, "A comparative study of the effects of cholesterol and sclareol, a bioactive labdane type diterpene on phospholipid bilayers," Chem Phys Lipids, vol. 133, no. 2, pp. 125-134, 2005.

[13] X. C. Tombokan, R. M. Aguda, D. A. Danehowe, P. K. Kilpatrick, and R. G. Carbonell, "Three-component phase behavior of the sclareol-ethyl lactate-carbon dioxide system for GAS applications," $J$ Supercrit Fluids, vol. 45, no. 2, pp. 146-155, 2008.

[14] Sclareol. [Online].

Available: http://www.thegoodscentscompany.com/data/rw1018631.html

[15] M. M. Finney, D. A. Danehower, and J. D. Burton, "Gas chromatographic method for the analysis of allelopathic natural products in rye (Secale cereale L.)," J Chromatogr A., vol. 1066, no. 1-2, pp. 249-253, 2005.

[16] R. M. Aguda, "Modeling the solubility of sclareol in organic solvents using solubilty parameters," Master of Science Thesis, North Carolina State University, August 2007.

[17] Chemical Database, Sci Finder. [Online]. Available: http://SciFinder.com
[18] M. Kakran, N. G. Sahoo, and L. Li, "Dissolution enhancement of quercetin through nanofabrication, complexation and solid dispersion," Colloid and Surfaces B: Biointerfaces, vol. 88, no. 1, pp. 121-130, 2011.

[19] R. Bogel-Lukasik, L. M. N. Goncalves, and E. Bogel-Lukasik, "Phase equilibrium phenomena in solutions involving tannins, flavonoids and ionic liquids," Green Chemistry, vol. 12, no. 11, pp. 1947-1953, 2010

[20] C.-C. Chen and P. A. Crafts, "Correlation and prediction of drug molecule solubility in mixed solvent systems with the nonrandom two-liquid segment activity coefficient (NRTL - SAC) model," Ind Eng Chem Res, pp. 4816-4824, 2006.

[21] H. Tung, J. Tabora, N. Variankaval, D. Bakken, and C.-C. Chen, "Prediction of pharmaceutical solubility via NRTL-SAC and COSMO-SAC," J Pharm Sci., vol. 97, no. 5, pp. 1813-1820, 2008.

[22] S. Tanveer, Y. Hao, and C.-C. Chen, "Introduction to solid-fluid equilibrium modeling," Chem Eng Prog, vol. 110, pp. 37-47, 2014.

[23] A. Klamt, "Conductor-like screening model for real solvents: A new approach to the quantitative calculation of solvation phenomena," $J$ Phys Chem, vol. 99, no. 7, pp. 2224-2235, 1995

[24] S.-T. Lin, "Sandler SI. A priori phase equilibrium prediction from a segment contribution solvation model," Ind Eng Chem Res., vol. 41, no. 5, pp. 899-913, 2002.

[25] E. Mullins, R. Oldland, Y. A. Liu et al., "Sigma-profile database for using COSMO-based thermodynamic methods," Ind Eng Chem Res., vol. 45, no. 12, pp. 4389-4415, 2006

[26] E. Mullins, Y. A. Liu, A. Ghaderi, and S. D. Fast, "Sigma profile database for predicting solid solubility in pure and mixed solvent mixtures for organic pharmacological compounds with COSMO-based thermodynamic methods," Ind Eng Chem Res, vol. 47, no. 5, pp 1707-1725, 2008

[27] Accelrys. Biovia materials studio overview. Mater Stud Overv. [Online]. Available: http://accelrys.com/products/datasheets/materials-studio-overview.pd $\mathrm{f}$

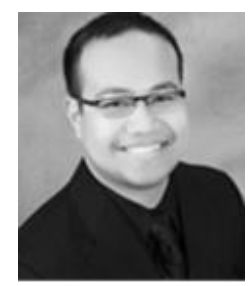

Remil M. Aguda has a bachelor of science degree in chemical engineering (cum laude) from the University of the Philippines Los Banos in 2001. He performed this research work as part of his master of science thesis in chemical engineering at North Carolina State University, USA in 2007. Afterwards, he worked as a process development engineer in a biotechnology company, Talecris Biotherapeutics, Research Triangle Park, NC, USA for 5 years and as faculty at the University of the Philippines Los Banos for 2 years. He is currently a PhD student at North Carolina State University. His research interest as a graduate student involves development and characterization of biomaterials.

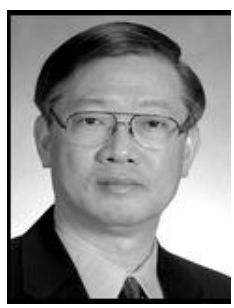

Chau-Chyun Chen has a bachelor of science degree in chemistry from National Taiwan University in 1973, obtained his master of science and doctor of science degrees in chemical engineering from Massachusetts Institute of Technology in 1977 and 1980 respectively. He co-founded a process simulation company, Aspen Technology, Inc. in 1981 then elected to the U.S. National Academy of Engineering in 2005. He is currently the Jack Maddox Distinguished Chair in Engineering, Department of Chemical Engineering, Texas Tech University. His research publications, patents, and invited lectures are on molecular thermodynamics, thermophysical properties and fluid phase equilibria; petroleum crude characterization, hydraulic fracturing, flow-back fluids; carbon dioxide capture systems, energy storage systems and pharmaceutical solubility modeling. 